\title{
Synthesis and characterization of thermally resistant aromatic polyamide-metal complexes
}

\author{
Sandeep Rai ${ }^{1^{*}}$, Anjali Bajpai ${ }^{2}$, Snehal Lokhandwala ${ }^{1}$ \\ ${ }^{1}$ Shroff S R Rotary Institute of Chemical Technology, Bharuch, Gujarat 393002, India \\ ${ }^{2}$ Department of Chemistry, Government Model Science College (Autonomous), Jabalpur 482001, India \\ * Corresponding author. E-mail: sadeep1964@yahoo.co.in
}

Received: 13 July 2013, Revised: 30 September 2013 and Accepted: 18 October 2013

\section{ABSTRACT}

Amino group terminated oligomeric aromatic polyamides were prepared using phosphorylation technique and subsequently converted into Schiff's base coordination polymers by reaction with Co (II), Ni (II) and Cu (II) complexes of salicyladehyde $\left[\mathrm{M}(\mathrm{SAL})_{2}\right]$ and 2-hydroxy-1-naphthaldehyde [M(NAPHTHAL $\left.)_{2}\right]$. These polyamide metal complexes were characterized by elemental analysis, IR spectroscopy and thermo gravimetric analysis; and an oxygen and nitrogen coordinated structure was inferred. Magnetic moment values of the different products indicated the variation in geometry. Introduction of metal ions into the polyamide chains enhanced the thermal stability of the coordination polymers as compared to the respective polymeric ligands. As an extension of this simple and easy technique, the thermal stability of fibers, films, sheets and blocks of amino group containing polyamides can be increasing by introduction of metal ions through Schiff base formation. These polyamide Schiff base complexes are expected to show promising antimicrobial activities. Copyright $(9) 2014$ VBRI press.

Keywords: Polyamides; coordination polymers; phosphorylation; Schiff base complexes.

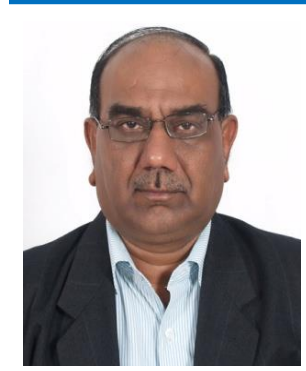

Sandeep Rai is a Professor in the Department of Chemistry, Shroff S.R. Rotary Institute of Chemical Technology, Ankleshwar, Gujarat, India. $\mathrm{He}$ received a $\mathrm{PhD}$ in polymer chemistry and has 22 years of rich industrial experience in R\&D, Product Development and R\&D Project Management related to Synthetic rubbers, Engineering Plastics \& Modification of natural polymers. He worked in reputed multinational companies in Global $R \& D$ centers and application development departments. His area of research interest includes the block and graft copolymerization, thermally resistant metal complexes, emulsion polymerization, modification of natural polymers, NBR/PVC blends, polymers for photovoltaic, biodegradable polymers etc. He has published more than 20 peer-reviewed research publications including 4 book chapters.

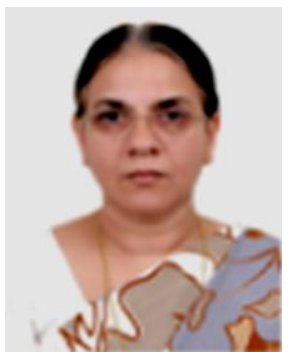

Anjali Bajpai was born in Jabalpur, India, and received her B.Sc. and M.Sc. degree from Government Science College, Jabalpur, in 1975 and 1977, respectively. She earned her Ph.D. degree in Chemistry in 1983 at the Rani Durgavati University, Jabalpur under the supervision of Professor D. D. Mishra in the field of coordination chemistry. She accepted an Assistant Professor position at Government Science College, Jabalpur in 1984. She has worked on organometallic chemistry as a visiting professor at Osaka City University, Osaka, Japan. She became Professor in 2006. Her research interests include polymer synthesis and characterization, coordination polymers, polymer nanocomposites.

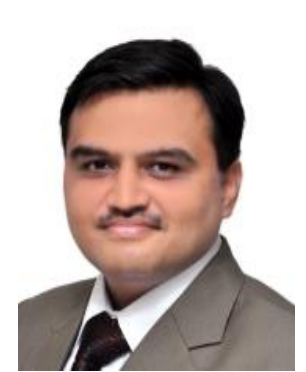

Snehal Lokhandwala is Associate Professor in the Department of Chemistry at Shroff S R Rotary Institute of Chemical Technology, Vataria, Ankleshwar. Dr Snehal received his M.Phil. and PhD. Degree in synthetic organic chemistry and have an experience of fifteen years in academics and industrial consultancy. His research interest includes heterocyclic chemistry, green synthesis, biopolymers etc. His industrial consultancy includes yield improvements, synthetic routes, environmentally friendly and green processes, applicable polymeric materials etc. He has published eight research articles in peer reviewed research journals. He is also research supervisor for several universities.

\section{Introduction}

Design of the structural skeleton, chemical functionalization and adjustment of dimensions are attracting the attention of material scientists [1]. Incorporation of coordination complexes into polymeric architecture is advantageous as it imparts the physicochemical properties of both partners to the product. Formation of supramolecular assemblies through metal ions embedded in a specific ligand field provides a route for synthesis of functional materials with diverse thermodynamic, kinetic, chemical, physical and structural properties [2-7]. Coordination polymers are infinite systems build up with metal ions and organic ligands as the 
main elementary units that are linked via coordination bonds and other weak chemical interactions. These compounds are also named metal-organic coordination networks or metal-organic frameworks. Metal-organic frameworks are a class of porous polymeric material, consisting of metal ions linked together by organic bridging ligands [8]. The ligand is a telechelic system which extends chain in the presence of a metal ion by polycondensationlike mechanism. The advantage of metal-ligand coordination is its high specificity and directionality and the strength of the metal coordination bond and the geometry of assembly vary by changing the metal ion [9].

Incorporation of metal ions in organic polymers is gaining impetus in search of materials which have thermal stability and good mechanical properties under conditions in which polymers based on carbon are unsatisfactory. It has been demonstrated that the thermo physical properties of ligands can be modified by coordination to transition metal complexes $[\mathbf{1 0}, \mathbf{1 1}]$. Coordination polymers may overcome difficulties arising from the insolubility of coordination compounds of high molecular weight thus can be fabricated easily to give materials of high mechanical strength. Coordination polymers can be synthesized by one of the following procedures: (i) favorable donor groups in the ligand may yield polymeric material during formation of metal complexes [12, 14], (ii) an organic polymer with donor groups in the main [15-19] or side chain [19] can coordinate to metal ions (iii) a monomeric metal complex may react with another organic compound to form polymeric complexes [20].

It was found that the complexes of substituted aryl thioureas with $\mathrm{Co}$ (II), $\mathrm{Ni}$ (II) and $\mathrm{Cu}$ (II) were polymeric and had high thermal stability $[\mathbf{1 1}, \mathbf{1 2}]$, however complexes of $\mathrm{Cu}$ (II) with the same ligands were monomeric with poor thermal stablility [21]. Therefore, it appeared that interaction with monomeric ligands does not always result in polymer-metal complexes, so perhaps it is better to synthesize polymeric metal complexes using polymeric ligands.

Aromatic polyamides, commonly known as polyaramid or aramid can be prepared by condensation of aromatic diamines and diacids similar to their aliphatic counterparts. However, synthesis of aromatic polyamides is somewhat difficult due to slow reaction rates of aromatic amines. They are being synthesized by low temperature condensation processes, which include interfacial and solution polymerization techniques. Another important and useful method is phosphorylation technique [22]. The present work was planned to systematically develop, thermally resistant polymer metal complexes for aerospace application using soluble oligomers of amino group terminated functional aromatic polyamides as ligand. Terephthalic acid and various aromatic amines, namely 4,4'-diaminodiphenyl methane, 4,4'-aminodiphenylether and 4,4'-diaminodiphenyl sulphone were condensed using a simple and easy phoshphorylation technique. The oligomeric polyamides were then linked through interaction with metal complexes of salicylaldehyde and 2hydroxy-1- naphthaldehyde to yield coordination polymers incorporating Schiff base structure. These polyamide Schiff base complexes are expected to show increased thermal stability and promising antimicrobial activities as observed with other polymeric Schiff base complexes [23-24].

Various Schiff bases based on aldehydes and aromatic diamines were extensively studied and were critically reviewed [25]. Schiff bases were reported to exhibit biological properties, such as, antibacterial, antifungal activities [26-27]. Few polymeric complexes with Schiff base structures have been synthesized from aromatic amines and phenolic aldehydes. These metal complexes have been widely studied because of their anticancer and herbicidal applications [28-29].

\section{Experimental}

\section{Materials}

All the materials used were of analytical or equivalent grades. Salicylaldehyde was from E-Merck, India and 2hydroxy ${ }^{-1}$-naphthaldehyde (A.G.) was from Fluka, A.G. 4,4'-Diaminodiphenylmethane, 4,4'-diaminodiphenylether, 4,4'-diaminodiphenyl sulphone, acetates of cobalt (II), nickel (II) and copper (II) of A.R. grade were obtained from E. Merck, India and were used without further purification. Dimethyl formamide (DMF), dimethylsulphoxide (DMSO) and pyridine were of GR grade products of Qualigens, Glaxo, India and were distilled before use.

\section{Preparation of amino terminated oligomeric polyamides (Aramid)}

Terephthalic acid $(0.1 \mathrm{~mol})$, respective diamines $(0.12 \mathrm{~mol})$ and tri phenyl phosphite were dissolved in a mixture of DMF $(150 \mathrm{~mL})$ and pyridine $(30 \mathrm{~mL})$. The reaction mixture was refluxed at $80^{\circ} \mathrm{C}$ for $1.5 \mathrm{~h}$ under nitrogen atmosphere. The amino group terminated oligomers were precipitated out by addition of excess of distilled methanol. The precipitated products were washed several times with methanol, filtered under suction and then dried in an air oven at $80^{\circ} \mathrm{C}$ for $20 \mathrm{~h}$.

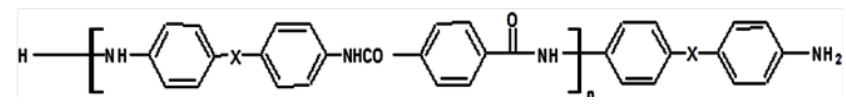

$\mathrm{X}=-\mathrm{CH}_{2}$ - for poly(methylenediphenyleneterephthalamide), PMDTA

$=-\mathrm{SO}_{2}$ - for poly(sulphonediphenyleneterephthalamide), PSDTA

$=-\mathrm{O}-\mathrm{m}$ for poly (etherdiphenyleneterephthalamide $)$, PODTA

The oligomers were characterized by IR spectroscopy and elemental analysis. The mass average molecular mass $\overline{M w}$ was calculated by viscometery using the following equation given by H. Aoki [30].

$[\eta]=(9.9 \times 10-4) \overline{M w} \times 0.8$ 


\section{Preparation of metal-aldehyde complexes}

The metal-aldehyde complexes were prepared by refluxing aqueous solutions of acetates of cobalt (II), nickel (II) and copper (II) with ethanolic solutions of salicyldehyde or 2 hydroxy-1-naphthaldehyde in respective preparations under magnetic stirring for 2-3 h. The coloured solid complexes thus precipitated were filtered, washed with ethanol followed by ether and then dried in an oven at $60^{\circ} \mathrm{C}$. The complexes were characterized by IR spectroscopy and elemental analysis.

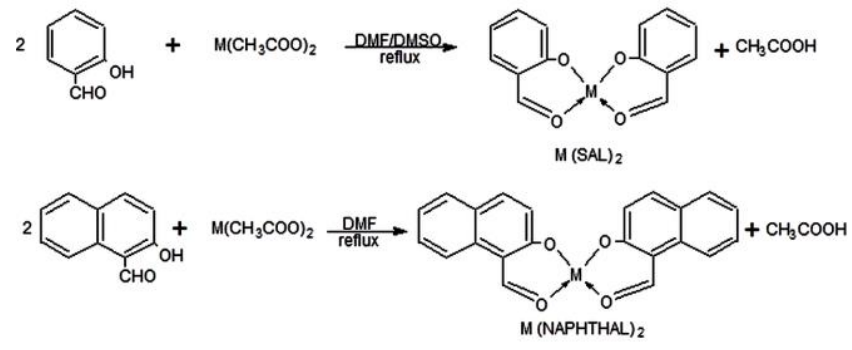

where $M=\mathrm{Co}(I I), \mathrm{Cu}(\mathrm{II})$ or Ni(II) $; \mathrm{SAL}=$ Salicylaldehyde; NAPHTHAL = Naphthaldehyde

\section{Synthesis of aramid-metal complexes}

Equimolar solutions of metal aldehydes and the aminoterminated oligomers in $50 \mathrm{~mL}$ hot DMF were refluxed on a heating mantle for about 6-8 h until coloured precipitates were obtained. The products were filtered, washed repeatedly with hot DMF and alcohol, and then dried. The aramid-metal complexes were coloured, powdery solids, insoluble in water and common organic solvent. The reaction scheme for the synthesis of aramid-metal complexes is given in Fig. 1.
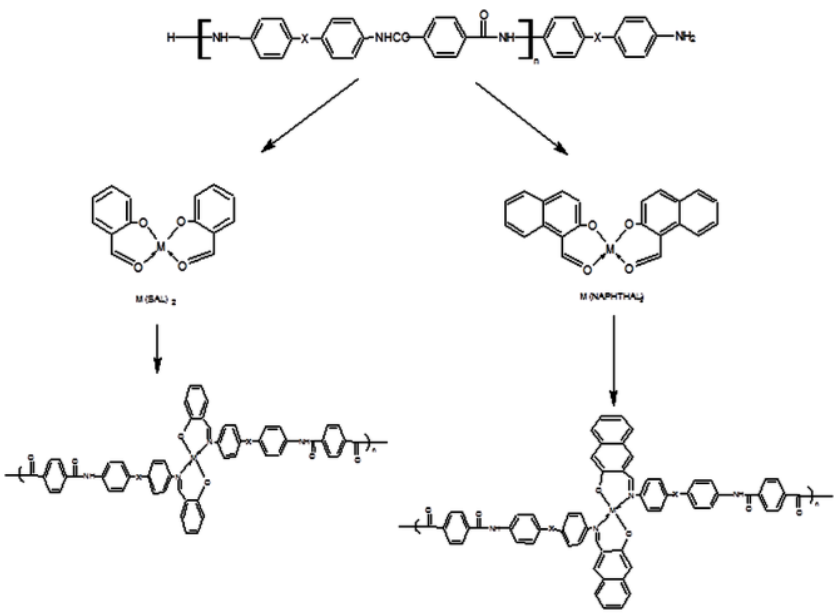

Fig. 1. Reaction scheme for the synthesis of aramid-metal complexes

\section{Characterization}

Elemental analysis of aramids and their coordination polymers were carried out on Perkin Elmer Elemental Analyzer model 2400. The metal contents were determined by complexometric titration with EDTA after digesting the coordination polymers with fuming nitric acid. Molecular weights of the coordination polymers could not be determined due to their insoluble nature.
IR spectra of the ligand and the coordination polymers were recorded on a Perkin Elmer Infrared Spectrophotometer Model 1430 using CsI pellets in 4000$200 \mathrm{~cm}^{-1}$ range. The magnetic susceptibility measurements were carried out at room temperature with a guoy's balance using $\mathrm{HgCo}(\mathrm{NCS})_{4}$ as a calibrant. Thermo gravimetric analyses were performed on a Perkin-Elmer Thermal Analyzer TGA 7 with professional computer 7700 in an inert atmosphere at a heating rate of $20^{\circ} \mathrm{C} / \mathrm{min}$.

Table 1A. Analytical data of PMDTA and its metal complexes.

\begin{tabular}{|c|c|c|c|c|c|}
\hline \multirow{2}{*}{ S. No. } & \multirow{2}{*}{ Compound } & \multicolumn{4}{|c|}{ Elemental Analysis * } \\
\hline & & $\% C$ & $\% \mathrm{H}$ & $\% \mathrm{~N}$ & $\% \mathrm{M}$ \\
\hline 1. & $\begin{array}{l}\text { PMDTA } \\
\mathrm{C}_{139} \mathrm{H}_{110} \mathrm{~N}_{14} \mathrm{O}_{12} \cdot 9 \mathrm{H}_{2} \mathrm{O}\end{array}$ & $\begin{array}{l}71.6 \\
(71.5)\end{array}$ & $\begin{array}{l}5.5 \\
(5.0)\end{array}$ & $\begin{array}{l}8.4 \\
(9.0)\end{array}$ & - \\
\hline 2. & $\begin{array}{c}\text { PMDTA-Co(lll-Sal' } \\
\left(\mathrm{C}_{278} \mathrm{H}_{212} \mathrm{~N}_{28} \mathrm{O}_{26}\right)\left(\mathrm{Co}(\mathrm{II}) \mathrm{C}_{14} \mathrm{H}_{10} \mathrm{O}_{2}\right)_{3} \cdot 18 \mathrm{H}_{2} \mathrm{O}\end{array}$ & $\begin{array}{l}70.0 \\
(70.0)\end{array}$ & $\begin{array}{l}5.1 \\
(4.8)\end{array}$ & $\begin{array}{l}7.2 \\
(7.9)\end{array}$ & $\begin{array}{l}3.2 \\
(3.3)\end{array}$ \\
\hline 3. & $\begin{array}{l}\text { PMDTA-Ni(II)-Sal' } \\
\left(\mathrm{C}_{278} \mathrm{H}_{212} \mathrm{~N}_{28} \mathrm{O}_{26}\right)\left(\mathrm{Ni}(\mathrm{II}) \mathrm{C}_{14} \mathrm{H}_{10} \mathrm{O}_{2}\right)_{3} \cdot 18 \mathrm{H}_{2} \mathrm{O}\end{array}$ & $\begin{array}{l}70.0 \\
(69.7)\end{array}$ & $\begin{array}{l}5.0 \\
(4.6)\end{array}$ & $\begin{array}{l}7.2 \\
(7.2)\end{array}$ & $\begin{array}{l}3.1 \\
(3.5)\end{array}$ \\
\hline 4. & $\begin{array}{c}\text { PMDTA-Cu(II)-Sal' } \\
\left(\mathrm{C}_{278} \mathrm{H}_{212} \mathrm{~N}_{28} \mathrm{O}_{26}\right)\left(\mathrm{Cu}(\mathrm{II}) \mathrm{C}_{14} \mathrm{H}_{10} \mathrm{O}_{2}\right)_{3} \cdot 18 \mathrm{H}_{2} \mathrm{O}\end{array}$ & $\begin{array}{l}69.8 \\
(70.0)\end{array}$ & $\begin{array}{l}5.0 \\
(4.3)\end{array}$ & $\begin{array}{l}7.1 \\
(7.7)\end{array}$ & $\begin{array}{r}3.4 \\
(3.5)\end{array}$ \\
\hline 5 & $\begin{array}{l}\text { PMDTA-Co(II)- Naphthal' } \\
\left(\mathrm{C}_{278} \mathrm{H}_{212} \mathrm{~N}_{28} \mathrm{O}_{26}\right)\left(\mathrm{Co}(\mathrm{II}) \mathrm{C}_{22} \mathrm{H}_{14} \mathrm{O}_{2}\right)_{3} \cdot 18 \mathrm{H}_{2} \mathrm{O}\end{array}$ & $\begin{array}{r}71.3 \\
(70.2)\end{array}$ & $\begin{array}{l}5.0 \\
(4.6)\end{array}$ & $\begin{array}{l}6.8 \\
(7.9)\end{array}$ & $\begin{array}{l}3.1 \\
(3.5)\end{array}$ \\
\hline 6. & $\begin{array}{c}\text { PMDTA-Ni(III)- Naphthal' } \\
\left(\mathrm{C}_{278} \mathrm{H}_{212} \mathrm{~N}_{28} \mathrm{O}_{26}\right)\left(\mathrm{Ni}(\mathrm{II}) \mathrm{C}_{22} \mathrm{H}_{14} \mathrm{O}_{2}\right)_{3} \cdot 18 \mathrm{H}_{2} \mathrm{O}\end{array}$ & $\begin{array}{c}71.3 \\
(71.2)\end{array}$ & $\begin{array}{l}5.0 \\
(4.8)\end{array}$ & $(7.5)$ & $\begin{array}{l}3.0 \\
(3.2)\end{array}$ \\
\hline 7. & $\begin{array}{c}\text { PMDTA-Cu(II)- Naphthal' } \\
\left(\mathrm{C}_{278} \mathrm{H}_{212} \mathrm{~N}_{28} \mathrm{O}_{26}\right)\left(\mathrm{Cu}(\mathrm{II}) \mathrm{C}_{22} \mathrm{H}_{14} \mathrm{O}_{2}\right)_{3} .18 \mathrm{H}_{2} \mathrm{O}\end{array}$ & $\begin{array}{l}71.2 \\
(70.4)\end{array}$ & $\begin{array}{l}5.0 \\
(4.6)\end{array}$ & $\begin{array}{l}6.8 \\
(7.2)\end{array}$ & $\begin{array}{l}3.3 \\
(4.0)\end{array}$ \\
\hline
\end{tabular}

"In every case the upper values represent the observed results and those in parentheses represent the theoretically calculated values.

Table 1B. Analytical data of PSDTA and its metal complexes.

\begin{tabular}{|c|c|c|c|c|c|}
\hline \multirow[b]{2}{*}{ S. No. } & \multirow[b]{2}{*}{ Compound } & \multicolumn{4}{|c|}{ Elemental Analysis * } \\
\hline & & $\% \mathrm{C}$ & $\% \mathrm{H}$ & $\% \mathrm{~N}$ & $\% \mathbf{M}$ \\
\hline \multirow[t]{2}{*}{1.} & PSDTA & 60.4 & 3.9 & 7.99 & - \\
\hline & $\mathrm{C}_{152} \mathrm{H}_{110} \mathrm{~N}_{16} \mathrm{O}_{30} \mathrm{~S}_{8} \cdot 7 \mathrm{H}_{2} \mathrm{O}$ & $(61.0)$ & $(4.1)$ & $(7.42)$ & - \\
\hline \multirow[t]{2}{*}{2.} & PSDTA-Co(II)-Sal' & 61.2 & 3.50 & 6.98 & 2.0 \\
\hline & $\begin{array}{l}\left(\mathrm{C}_{152} \mathrm{H}_{110} \mathrm{~N}_{16} \mathrm{O}_{30} \mathrm{~S}_{8} .7 \mathrm{H}_{2} \mathrm{O}\right)(\mathrm{Co}(\mathrm{II}) \\
\left.\mathrm{C}_{14} \mathrm{H}_{10} \mathrm{O}_{2}\right)_{6}\end{array}$ & $(60.6)$ & $(4.07)$ & $(6.70)$ & $(2.1)$ \\
\hline \multirow[t]{2}{*}{3.} & PSDTA-Ni(II)-Sal' & 61.4 & 3.77 & 6.87 & 2.1 \\
\hline & $\begin{array}{l}\left(\mathrm{C}_{152} \mathrm{H}_{110} \mathrm{~N}_{16} \mathrm{O}_{30} \mathrm{~S}_{8} .7 \mathrm{H}_{2} \mathrm{O}\right)(\mathrm{Ni}(\mathrm{II}) \\
\left.\mathrm{C}_{14} \mathrm{H}_{10} \mathrm{O} 2\right)_{6}\end{array}$ & $(60.6)$ & $(4.07)$ & $(6.70)$ & $(2.1)$ \\
\hline \multirow[t]{2}{*}{4.} & PSDTA-Cu(II)-Sal' & 60.0 & 3.66 & 6.50 & 2.3 \\
\hline & $\begin{array}{l}\left(\mathrm{C}_{152} \mathrm{H}_{110} \mathrm{~N}_{16} \mathrm{O}_{30} \mathrm{~S}_{8} \cdot 7 \mathrm{H}_{2} \mathrm{O}\right)(\mathrm{Cu}(\mathrm{II}) \\
\left.\mathrm{C}_{14} \mathrm{H}_{10} \mathrm{O}_{2}\right)_{6}\end{array}$ & $(60.5)$ & $(4.06)$ & $(6.69)$ & (2.3) \\
\hline \multirow[t]{2}{*}{5.} & PSDTA-Co(II)-Naphthal' & 62.0 & 2.96 & 7.20 & 2.0 \\
\hline & $\begin{array}{l}\left(\mathrm{C}_{152} \mathrm{H}_{110} \mathrm{~N}_{16} \mathrm{O}_{30} \mathrm{~S}_{8} \cdot 7 \mathrm{H}_{2} \mathrm{O}\right)(\mathrm{Co}(\mathrm{II}) \\
\left.\mathrm{C}_{14} \mathrm{H}_{10} \mathrm{O}_{2}\right)_{5}\end{array}$ & $(61.9)$ & $(4.06)$ & $(6.43)$ & (2.1) \\
\hline \multirow[t]{2}{*}{6.} & PSDTA-Ni(II)- Naphthal' & 62.0 & 3.54 & 6.99 & 2.0 \\
\hline & $\begin{array}{l}\left(\mathrm{C}_{152} \mathrm{H}_{110} \mathrm{~N}_{16} \mathrm{O}_{30} \mathrm{~S}_{8} .7 \mathrm{H}_{2} \mathrm{O}\right)(\mathrm{Ni}(\mathrm{II}) \\
\left.\mathrm{C}_{14} \mathrm{H}_{10} \mathrm{O}_{2}\right)_{5}\end{array}$ & $(61.9)$ & $(4.06)$ & $(6.43)$ & (2.1) \\
\hline \multirow[t]{2}{*}{7.} & PSDTA-Cu(II)-Naphthal' & 61.2 & 3.24 & 6.96 & 2.2 \\
\hline & $\begin{array}{l}\left(\mathrm{C}_{152} \mathrm{H}_{110} \mathrm{~N}_{16} \mathrm{O}_{30} \mathrm{~S}_{8} .7 \mathrm{H}_{2} \mathrm{O}\right)(\mathrm{Cu}(\mathrm{II}) \\
\left.\mathrm{C}_{14} \mathrm{H}_{10} \mathrm{O}_{2}\right)_{5}\end{array}$ & $(61.8)$ & $(4.06)$ & $(6.42)$ & (2.3) \\
\hline
\end{tabular}

*In every case the upper values represent the observed results and those in parentheses represent the theoretically calculated values.

\section{Results and discussion}

The analytical data for the ligands and their metal complexes are presented in Table $\mathbf{1 A}, \mathbf{B}$ and $\mathbf{C}$. The compositions and theoretical analytical results are based on assumed structures. In case of PMDTA number of repeat units (n) is taken as 6 for the theoretical calculations. However, the average of molecular masses calculated on the basis of $n=5$ and $n=6$ respectively, is 2002 which is 
very close to the experimentally determined $\overline{\mathrm{Mw}}=2000$. 1.5 water molecules were considered to be absorbed per CONH group [15]. The experimentally determined $\overline{M w}$ for PSDTA ligand is 3056. The theoretically calculated value of molecular mass, by using seven repeat units and one water molecule per amide group comes out to be 3020 which can be considered appreciably close to the experimental value. The molecular mass determined experimentally for PODTA was 2960. The molecular formula for the ligand PODTA is suggested as

\section{$\mathrm{H}-\left(-\mathrm{NH}-\mathrm{C}_{6} \mathrm{H}_{4}-\mathrm{O}-\mathrm{C}_{6} \mathrm{H}_{4}-\mathrm{NHCO}\left(\mathrm{H}_{2} \mathrm{O}\right)-\mathrm{C}_{6} \mathrm{H}_{4}-\mathrm{CO}-\right)_{6}-\mathrm{NH}-$ $\mathrm{C}_{6} \mathrm{H}_{4}-\mathrm{O}-\mathrm{C}_{6} \mathrm{H}_{4}-\mathrm{NH}_{2}$}

It was observed that the deviations of the experimental values of elemental analysis from the theoretical ones were beyond experimental error. This discrepancy between the calculated and observed results may be due to the strong moisture pick up tendency of aramids.

Table 1C. Analytical data of PODTA and its metal complexes.

\begin{tabular}{|c|c|c|c|c|c|}
\hline \multirow{2}{*}{ S. No. } & \multirow{2}{*}{ Compound } & \multicolumn{4}{|c|}{ Elemental Analysis * } \\
\hline & & $\% \mathrm{C}$ & $\% \mathrm{H}$ & $\% \mathrm{~N}$ & $\% \mathrm{M}$ \\
\hline \multirow[t]{2}{*}{1.} & PODTA & 69.35 & 4.4 & 8.47 & - \\
\hline & $\mathrm{C}_{172} \mathrm{H}_{140} \mathrm{~N}_{18} \mathrm{O}_{33}$ & (69.92) & $(4.5)$ & $(9.05)$ & - \\
\hline \multirow[t]{2}{*}{2.} & PODTA-Co(II)-Sal' & 68.52 & 4.60 & 7.62 & 2.14 \\
\hline & $\begin{array}{l}\left(\mathrm{C}_{172} \mathrm{H}_{124} \mathrm{~N}_{18} \mathrm{O}_{25} .8 \mathrm{H}_{2} \mathrm{O}\right)_{5}(\mathrm{Co} \text { (II) } \\
\left.\mathrm{C}_{14} \mathrm{H}_{10} \mathrm{O}_{2}\right)_{6}\end{array}$ & $(68.28)$ & $(3.92)$ & (7.68) & (2.20) \\
\hline \multirow[t]{2}{*}{3.} & PODTA-Ni(II)-Sal' & 68.38 & 4.57 & 7.44 & 2.60 \\
\hline & $\left.\mathrm{C}_{14} \mathrm{H}_{10} \mathrm{O}_{2}\right)_{3}$ & $(69.08)$ & (2.96) & (7.77) & (2.59) \\
\hline \multirow[t]{2}{*}{4.} & PODTA-Cu(II)-Sal' & 68.52 & 4.60 & 7.74 & 1.95 \\
\hline & $\mathrm{C}_{172} \mathrm{H}_{124} \mathrm{~N}_{18} \mathrm{O}_{25} .8 \mathrm{H}_{2} \mathrm{OCu}(\mathrm{II}) \mathrm{C}_{14} \mathrm{H}_{10} \mathrm{O}_{2}$ & $(68.20)$ & $(3.69)$ & (7.56) & $(2.00)$ \\
\hline \multirow[t]{2}{*}{5.} & PODTA-Co(II)-Naphthal' & 69.54 & 4.55 & 7.12 & 2.50 \\
\hline & $\left.\mathrm{C}_{14} \mathrm{H}_{10} \mathrm{O}_{2}\right)_{3}$ & $(70.02)$ & $(3.68)$ & (7.68) & (2.34) \\
\hline \multirow[t]{2}{*}{6.} & PODTA-Ni(II)-Naphthal' & 69.51 & 4.57 & 7.25 & 2.25 \\
\hline & $\left.\mathrm{C}_{14} \mathrm{H}_{10} \mathrm{O}_{2}\right)_{4}$ & $(72.24)$ & $(3.66)$ & (7.54) & $(2.34)$ \\
\hline \multirow[t]{2}{*}{7.} & PODTA-Cu(II)-Naphthal' & 69.39 & 4.56 & 7.23 & 2.43 \\
\hline & $\left.\mathrm{C}_{14} \mathrm{H}_{10} \mathrm{O}_{2}\right)_{4}$ & $(69.20)$ & $(4.04)$ & (7.98) & $(2.40)$ \\
\hline
\end{tabular}

*In every case the upper values represent the observed results and those in parentheses represent the theoretically calculated values.

Puffer and Sebenda [31] have described sorption and desorption isotherms of water for several crystalline as well as amorphous polyamides and the model amides. They have shown that in Nylon 6, three molecules of water are sorbed on two neighboring amide groups. The first molecule is firmly bound between the CO groups and the other two molecules form $\mathrm{H}$-bonds between the $\mathrm{CO}$ and the $\mathrm{NH}$ groups (loosely bound water). In nylons two to six water molecules are sorbed on two amide groups, probably as firmly bound water. Nylon 7 stands somewhere between the two groups. We reported earlier that poly(methylene diphenylene terphthalamide) and its coordination polymers exhibited moisture pick up by the polyamide as well as its coordination polymers [32]. The numbers of water molecules sorbed to the amide groups were found to be1.5 per CONH group excluding the capillary condensation.

For PSDTA and PODTA consideration of one water molecule per amide group showed better agreement with the experimental analytical data. A perusal of Tables $1 \mathrm{a}, \mathrm{b}$ and c, however, indicated that in every case the experimental values deviate appreciably from the theoretical values. A wide poly dispersity of the oligomeric ligands may be responsible for the deviation. Similarly for the Schiff base metal complexes also the stoichiometry may not be uniform. The terminal units may have variable compositions as shown in Fig. 1. For the purpose of theoretical calculations structure $\mathrm{C}$ has been used. However, all the other structural possibilities of end units as give in the Fig. 1. Some other combinations are also possible. Because of polymeric nature the possibility of structural defects is always there. Further, the exact amount of adsorbed and capillary condensation water cannot be calculated.

Table 2. IR spectral assignments of aramids and their metal complexes.

\begin{tabular}{|c|c|c|c|c|c|c|}
\hline \multirow[t]{2}{*}{ Compounds } & \multicolumn{6}{|c|}{ Assignments $\mathrm{cm}^{-1}$} \\
\hline & $\nu_{\mathrm{NH}}$ & Amide (I) & Amide (II) & $\nu_{\mathrm{C}=\mathrm{N}}$ & $\nu_{M-O}$ & $\nu_{M-N}$ \\
\hline PMDTA & $3400-3200 \mathrm{br}$ & $1650 \mathrm{~s}$ & $1520 \mathrm{~s}$ & -- & -- & -- \\
\hline PMDTA-Co(II)-Sal' & $3400-3180 \mathrm{br}$ & $1660 \mathrm{~s}$ & $1525 \mathrm{~s}$ & $1550 \mathrm{sh}$ & $680 \mathrm{~s}$ & $500 w$ \\
\hline PMDTA-Ni(II)-Sal' & $3500-3160 \mathrm{br}$ & $1650 \mathrm{~s}$ & $1520 \mathrm{~s}$ & $1560 \mathrm{sh}$ & $660 \mathrm{~m}$ & $495 \mathrm{~m}$ \\
\hline PMDTA-Cu(II)-Sal' & $3600-3160 \mathrm{br}$ & $1640 \mathrm{~s}$ & $1530 \mathrm{~s}$ & $1545 \mathrm{sh}$ & $670 \mathrm{~s}$ & $495 \mathrm{~s}$ \\
\hline PMDTA-Co(II)-Naphthal' & $3500-3240 \mathrm{br}$ & 1650 & $1530 \mathrm{~s}$ & $1540 \mathrm{sh}$ & $650 \mathrm{~m}$ & $485 \mathrm{~m}$ \\
\hline PMDTA-Ni(II)-Naphthal' & $3500-3200 \mathrm{br}$ & $1655 \mathrm{~s}$ & $1530 \mathrm{~s}$ & $1560 \mathrm{sh}$ & $665 \mathrm{~m}$ & $500 \mathrm{~m}$ \\
\hline PMDTA-Cu(II)-Naphthal' & $3560-3200 \mathrm{br}$ & $1655 \mathrm{~s}$ & $1530 \mathrm{~s}$ & $1550 \mathrm{sh}$ & $660 \mathrm{~m}$ & $490 \mathrm{~m}$ \\
\hline PSDTA & $3350 \mathrm{~s}$ & $1690 \mathrm{~s}$ & $1540 \mathrm{~s}$ & -- & -- & -- \\
\hline PSDTA-Co(II)-Sal' & $3350 \mathrm{~s}$ & $1690 \mathrm{~s}$ & $1540 \mathrm{~s}$ & $1560 \mathrm{~s}$ & $400 \mathrm{~s}$ & $400 \mathrm{~s}$ \\
\hline PSDTA-Ni(II)-Sal' & $3350 \mathrm{~s}$ & $1695 \mathrm{~s}$ & $1540 \mathrm{~s}$ & $1560 \mathrm{~s}$ & $430 \mathrm{~s}$ & $430 \mathrm{~m}$ \\
\hline PSDTA-Cu(II)-Sal' & $3350 \mathrm{~s}$ & $1690 \mathrm{~s}$ & $1540 \mathrm{~s}$ & $1570 \mathrm{~s}$ & $410 \mathrm{~s}$ & $410 \mathrm{~s}$ \\
\hline PSDTA-Co(II)-Naphthal' & $3350 \mathrm{~s}$ & $1695 \mathrm{~s}$ & $1540 \mathrm{~s}$ & $1540 \mathrm{~s}$ & $400 \mathrm{~s}$ & $400 \mathrm{~s}$ \\
\hline PSDTA-Ni(II)-Naphthal' & $3350 \mathrm{~s}$ & $1690 \mathrm{~s}$ & $1540 \mathrm{~s}$ & $1575 \mathrm{~s}$ & $410 \mathrm{~s}$ & $410 \mathrm{~m}$ \\
\hline PSDTA-Cu(II)-Naphthal' & $3350 \mathrm{~s}$ & $1700 \mathrm{~s}$ & $1540 \mathrm{~s}$ & $1570 \mathrm{~s}$ & $415 \mathrm{~s}$ & $415 \mathrm{~m}$ \\
\hline PODTA & $3305 \mathrm{~s}$ & $1630 \mathrm{~s}$ & $1540 \mathrm{~s}$ & -- & -- & -- \\
\hline PODTA-Co(II)-Sal' & $3300 \mathrm{~s}$ & $1640 \mathrm{~s}$ & $1540 \mathrm{~s}$ & $1550 \mathrm{~s}$ & $520 \mathrm{~m}$ & $470 m$ \\
\hline PODTA-Ni(II)-Sal' & $3305 \mathrm{~s}$ & $1630 \mathrm{~s}$ & $1540 \mathrm{~s}$ & $1545 \mathrm{~s}$ & $540 \mathrm{~m}$ & $475 m$ \\
\hline PODTA-Cu(II)-Sal' & $3300 \mathrm{~s}$ & $1635 \mathrm{~s}$ & $1545 \mathrm{~s}$ & $1560 \mathrm{~s}$ & $530 \mathrm{~m}$ & $460 \mathrm{~m}$ \\
\hline PODTA-Co(II)-Naphthal' & $3305 \mathrm{~s}$ & $1630 \mathrm{~s}$ & $1540 \mathrm{~s}$ & $1560 \mathrm{~s}$ & $560 \mathrm{~m}$ & $480 w$ \\
\hline PODTA-Ni(II)-Naphthal' & $3305 \mathrm{~s}$ & $1640 \mathrm{~s}$ & $1545 \mathrm{~s}$ & $1565 \mathrm{~s}$ & $540 \mathrm{~m}$ & $470 \mathrm{~s}$ \\
\hline PODTA-Cu(II)-Naphthal' & $3300 \mathrm{~s}$ & $1630 \mathrm{~s}$ & $1540 \mathrm{~s}$ & $1570 \mathrm{~s}$ & $530 \mathrm{~m}$ & $460 \mathrm{~s}$ \\
\hline
\end{tabular}

\section{IR spectral studies}

The structurally important infrared spectral bands for the amino terminated oligomeric ligands and their metal complexes are depicted in Table 2. The assignments were based on the literature data [33]. The ir spectrum of ligand PSDTA exhibited a strong band at $3350 \mathrm{~cm}^{-1}$ which was attributed to $\mathrm{NH}$ of amide group. The characteristic bands of aromatic ring appeared at $3060 \mathrm{~cm}^{-1}$ for aromatic C-H stretching and at $940 \mathrm{~cm}^{-1}$ for C-H deformation. The band at $850 \mathrm{~cm}^{-1}$ is attributed to the p-substituted benzene ring vibrations. The amide $\mathrm{I}$ or $\mathrm{C}=\mathrm{O}$ band is observed at 1630 $\mathrm{cm}^{-1}$ which is the expected range $1680^{-1} 630 \mathrm{~cm}^{-1}$ for the amides. The amide II or $\mathrm{NH}$ deformation mode of amide group of PSDTA appeared at $1530 \mathrm{~cm}^{-1}$. The normal range 
of amide II band is $1600-1500 \mathrm{~cm}^{-1}$. Another band which was attributed to amide III or having main contribution from C-N stretching appeared at $1290 \mathrm{~cm}^{-1}$. The characteristic asymmetric and symmetric stretching modes of $\mathrm{SO}_{2}$ groups appeared at $1340 \mathrm{~cm}^{-1}$ and $1110 \mathrm{~cm}^{-1}$ respectively. . The amide $\mathrm{V}$ band appears at $725 \mathrm{~cm}^{-1}$.

In the IR spectrum of PMDTA a broad band due to $v \mathrm{NH}$ vibrations of amide and terminal amino groups appeared in $3400-3200 \mathrm{~cm}^{-1}$ range. The broadening of this band and the shifting towards higher frequency may be attributed to the H-bonding. Two strong bands due to symmetric and asymmetric $-\mathrm{CH}$ - stretching appear at 2940 and $2860 \mathrm{~cm}^{-1}$ and the $-\mathrm{CH}_{2}$ - bending vibration appear at $1410 \mathrm{~cm}^{-1}$. The characteristic band due to aromatic $\mathrm{CH}$ is observed at $3000-2900 \mathrm{~cm}^{-1}$. The amide I band with main contribution from the $\mathrm{C}=\mathrm{O}$ appears at $1650 \mathrm{~cm}^{-1}$. The bands due to amide II, III, IV and VI appeared at 1510, 1330, 640 and $590 \mathrm{~cm}^{-1}$ respectively. The out-of-plane $\delta \mathrm{NH}$ or the amide $\mathrm{V}$ was observed at $730 \mathrm{~cm}^{-1}$. Vibrations due to $\mathrm{p}$ substituted benzene rings are observed at $850 \mathrm{~cm}^{-1}$.

The ir spectrum of ligand PODTA shows an intense and sharp band at $3305 \mathrm{~cm}^{-1}$ which may be attributed to $y \mathrm{NH}$ of amide group of PODTA chain. The bands characteristic of aromatic rings appear near $3100 \mathrm{~cm}^{-1}$ for $\mathrm{yCH}$ (aromatic) and for $\mathrm{C}-\mathrm{H}$ in plane deformation at $920 \mathrm{~cm}^{-1}$. p-substituted benzene ring vibration appeared at $870 \mathrm{~cm}^{-1}$. Amide I and II appeared at 1630 and $1540 \mathrm{~cm}^{-1}$ respectively and the amide III appeared in the region $1315 \mathrm{~cm}^{-1}$. The characteristic band of diphenylene ether (C-O-C) appeared at $1240 \mathrm{~cm}^{-1}$. The amide $\mathrm{V}$ band appears at $725 \mathrm{~cm}^{-1}$. The ir spectra of the coordination polymers are compared with those of the respective ligands to elucidate the nature of coordination.

The amide II band appeared at $1520 \mathrm{~cm}^{-1}$ in PMDTA and at $1540 \mathrm{~cm}^{-1}$ in PSDTA and PODTA splitted upon coordination. The new band in $1545-1575 \mathrm{~cm}^{-1}$ region could be attributed to $\mathrm{C}=\mathrm{N}$ groups as an evidence for Schiff's base formation. Generally the azomethine group absorbs in the $1690-1580 \mathrm{~cm}^{-1}$ range, the appearance of this band in the lower range suggested the involvement of azomethine nitrogen in the coordination. Similar observation was made by Fisher and Stoufer [34]. They reported a downward shift in $\mathrm{C}=\mathrm{N}$ frequency by approximately $45-80 \mathrm{~cm}^{-1}$ on coordination. The negative shift in the $\mathrm{C}=\mathrm{N}$ frequency was attributed to the coordination through azomethine nitrogen and a greater extent of $\pi$-bonding between the metal atoms and the ligand molecules.

The other bands of the ligands appeared uninfluenced upon co-ordination suggesting non-involvement of amide groups of aramid in coordination. The characteristic absorptions due to acetate group could not be observed in the ir spectra of metal complexes thereby suggesting absence of acetate ions. The appearance of new bands in the far ir region attributed to $\mathrm{M}-\mathrm{O}$ and $\mathrm{M}-\mathrm{N}$ further confirmed the complexation through nitrogen and oxygen.

\section{Magnetic susceptibility measurements}

Magnetic moment values of aramid-metal complexes are summarized in Table 3. The magnetic moment values in 4.36-4.69 BM range for $\mathrm{Co}(\mathrm{II})$ complexes are consistent with the tetrahedral geometry [35]. The diamagnetic behavior of $\mathrm{Ni}$ (II) complexes indicated their square-planar geometry [36]. The square-planar geometry of $\mathrm{Cu}$ (II) complexes was indicated by the magnetic moment values in the range of $1.69-1.85 \mathrm{BM}$ [37-38]. On the basis of all the above studies a tentative structure as shown in Fig. 1 can be proposed for the complexes.

Table 3. Magnetic moment values for polyaramid-metal complexes.

\begin{tabular}{llll}
\hline S.No. & & \multicolumn{1}{c}{$\begin{array}{l}\text { Magnetic moment } \\
\mu_{\text {eff }} \text { B.M. }\end{array}$} & Geometry Proposed \\
\hline 1 & PMDTA-Co(II)-Sal' & 4.69 & Tetrahedral \\
2 & PMDTA-Ni(II)-Sal' & Diamagnetic & Square Planar \\
\hline 3 & PMDTA-Cu(II)-Sal' & 1.79 & Square Planar \\
4 & PMDTA-Co(II)-Naphthal' & 1.82 & Square Planar \\
5 & PMDTA-Ni(II)-Naphthal' & Diamagnetic & Square Planar \\
6 & PMDTA-Cu(II)-Naphthal' & 1.82 & Square Planar \\
7 & PSDTA-Co(II)-Sal' & 4.48 & Tetrahedral \\
8 & PSDTA-Ni(II)-Sal' & Diamagnetic & Square Planar \\
9 & PSDTA-Cu(II)-Sal' & 1.69 & Square Planar \\
10 & PSDTA-Co(II)-Naphthal' & 4.36 & Tetrahedral \\
11 & PSDTA-Ni(II)-Naphthal' & Diamagnetic & Square Planar \\
12 & PSDTA-Cu(II)-Naphthal' & 1.82 & Square Planar \\
13 & PODTA-Co(II)-Sal' & 4.68 & Tetrahedral \\
14 & PODTA-Ni(II)-Sal' & Diamagnetic & Square Planar \\
15 & PODTA-Cu(II)-Sal' & 1.77 & Square Planar \\
16 & PODTA-Co(II)-Naphthal' & 4.56 & Tetrahedral \\
17 & PODTA-Ni(II)-Naphthal' & PODTA-Cu(II)-Naphthal' & Square Planar \\
\hline 18 & & & Square Planar \\
\hline
\end{tabular}

\section{Thermo gravimetric analysis}

Thermo gravimetric data of aramid and their metal complexes are presented in Fig 2 A, B and C. Data of PMDTA and PODTA show that decomposition of these ligands commences above $100{ }^{\circ} \mathrm{C}$. The initial weight loss may be attributed to the loss of adsorbed water. The TG analyses of the ligand PSDTA was repeated several times but every time fluctuating results were obtained. This may be due to different amount of moisture absorbed by the different samples used for TGA. Generally 1.5 water molecules shown to be firmly bound per amide group and besides this capillary condensation were also possible ${ }^{[38]}$. To overcome the problem of variable results in TGA, a sample of PSDTA was heated up to $105^{\circ} \mathrm{C}$ for $6 \mathrm{~h}$ and cooled in vacuum desiccators. Then the TGA was carried out and no weight loss was observed up to $300{ }^{\circ} \mathrm{C}$.

Dine Hart et al. [39] determined the thermo oxidative stabilities of a number of aromatic polyamides derived from terephthaloyl chloride by isothermal thermo gravimetric analysis. They reported that the aramid based on terephthaloyl chloride and 4, 4'diaminodiphenylsulphone lost only $2.8 \%$ of weight in air at $300{ }^{\circ} \mathrm{C}$ after $2 \mathrm{~h}$. They also reported that aramid derived from 4, 4'-diaminodiphenylsulphone was more stable than that from 4, 4'-diaminodiphenylmethane.

PMDTA showed initial decomposition at $220{ }^{\circ} \mathrm{C}$ and second step decomposition at $510{ }^{\circ} \mathrm{C}$, above this 
temperature PMDTA shows a rapid weight loss and it attains constancy in weight above $650{ }^{\circ} \mathrm{C}$. Similarly PODTA ligand shows significant initial decomposition at $526.2{ }^{\circ} \mathrm{C}$ and constancy in weight is attained above 650 $700{ }^{\circ} \mathrm{C}$. PSDTA showed single step degradation pattern and onset temperature of decomposition was $338.8{ }^{\circ} \mathrm{C}$, thereafter a sharp decrease in weight was observed and at $650{ }^{\circ} \mathrm{C}$ ninety percent of weight was lost. The mechanism of thermal degradation of aramid metal complexes is proposed as below;
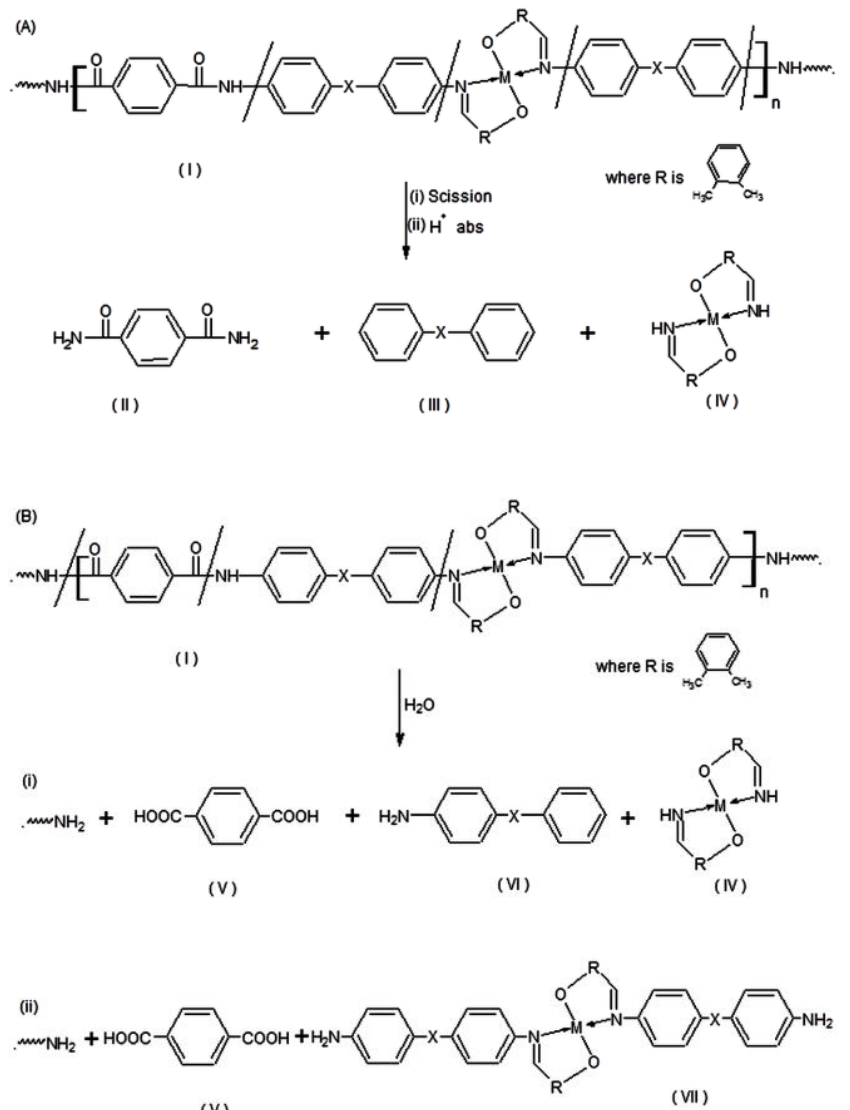

( $v$

(VII)

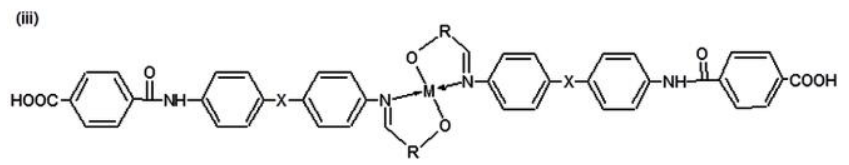

(VIII)

The ligands which show two step decomposition indicates the formation of intermediate products during thermal degradation process due to rupture of polyamide chain. The degradation of aramid takes place through the random scission of polymer chain into low molecular weight organic compounds and various volatile gaseous products like $\mathrm{CO}_{2}, \mathrm{NH}_{3}$, water, etc. are evolved.

The decomposition pattern of PSDTA was different than that for PMDTA or PODTA and its stability was also lesser. It decomposed almost completely into volatile products at $700{ }^{\circ} \mathrm{C}$, whereas PMDTA and PODTA retained 52 and 41 percent weights respectively at $700{ }^{\circ} \mathrm{C}$. It can be suggested that the different behavior of PSDTA may be due to fact that its preheated sample was employed for TGA, from which the adsorbed water molecules might have been removed and the aramid chains were not bound together strongly. Certainly the adsorbed water molecules might hold the different aramid chains through hydrogen bonding in case of PMDTA and PODTA. Therefore, it was inferred that the different chain environments may be responsible for the different degradation mechanisms. Sazanov et al [40] in their comparative thermal analysis (CTA) studies with thermally stable polyimides and model compounds concluded that the process of thermo oxidation was of successive character i.e. the defective fragments were 'burned out' before the main structure was oxidized.
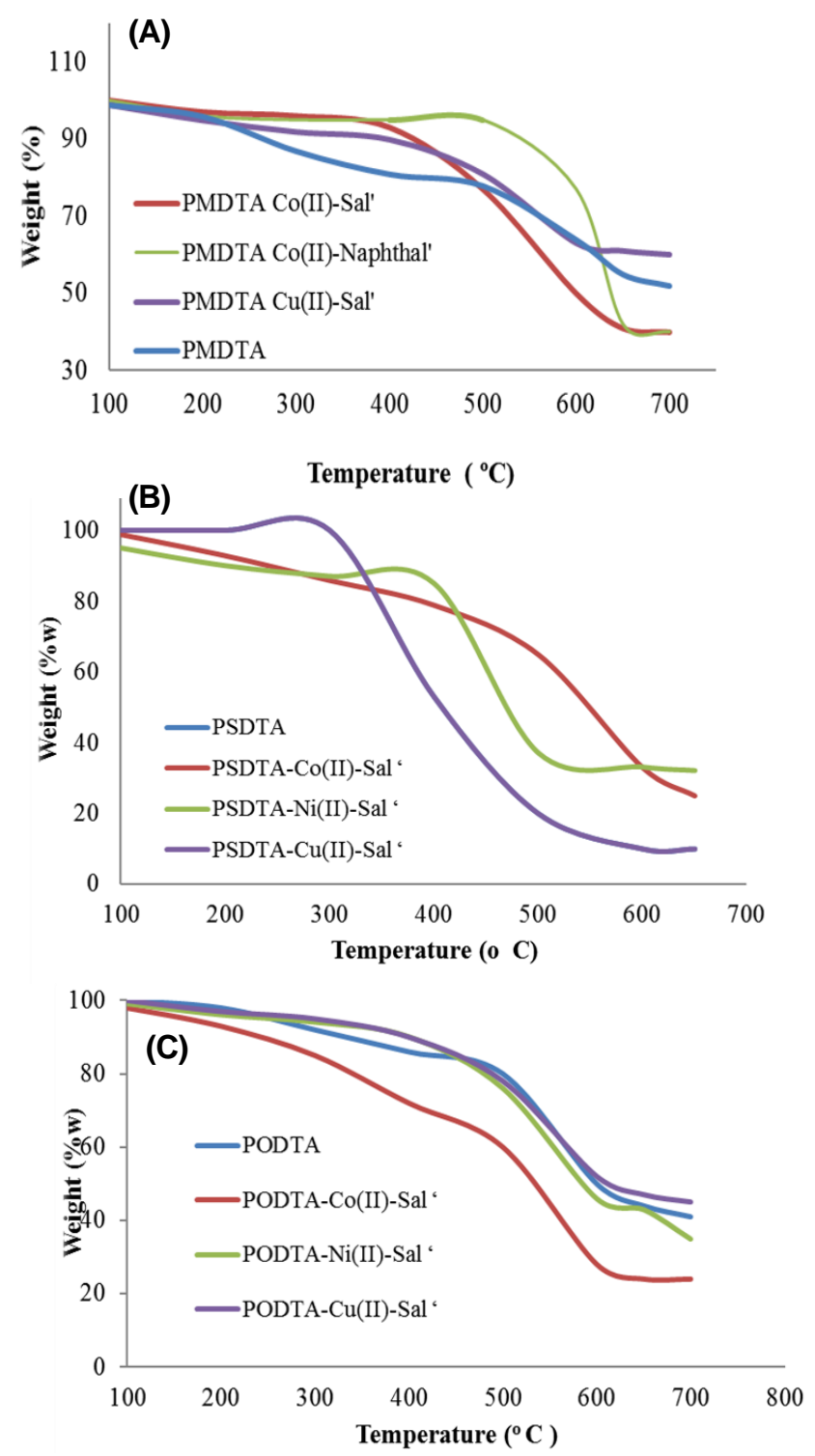

Fig. 2. (A) TGA curves of Aramids and their metal complexes, (B) TGA curves of Aramids and their metal complexes and (C) TGA curves of Aramids and their metal complexes.

On the basis of initial decomposition temperature the order of thermal stability for various ligands was found to be as follows:

PSDTA > PODTA > PMDTA 
Nishizaki and Fukani [41] have given an order of thermal stability for pyromellitimides using differential thermal analysis. The relative stability order of the polymers with respect to the aromatic linking group of the diamine component was given as follows:

$-\mathrm{C}_{6} \mathrm{H}_{4}-\mathrm{O}-\mathrm{C}_{6} \mathrm{H}_{4^{-}}>-\mathrm{C}_{6} \mathrm{H}_{4}-\mathrm{CH}_{2}-\mathrm{C}_{6} \mathrm{H}_{4^{-}}>-\mathrm{C}_{6} \mathrm{H}_{4}-\mathrm{SO}_{2}-\mathrm{C}_{6} \mathrm{H}_{4^{-}}$

On the basis of second step decomposition temperature the order of thermal stability for the aramid resembled with the thermal stability order amongst p-linked phenylene model compounds [42]. The order of thermal stability may be represented as:

Single bond >-O- >- $\mathrm{CH}_{2}>-\mathrm{S}-$

On comparing the residual percentage weight at $700{ }^{\circ} \mathrm{C}$ the order of stability was found to be

\section{PMDTA $>$ PODTA $>$ PSDTA}

The different orders of thermal stabilities were obtained for the ligands at different temperatures. Therefore, it appeared that it was difficult to correlate the data for polymeric substances with the behavior of analogous model compounds. It is to be mentioned here that the polymer chain environment often affects the course of degradation, which could not be predicted from the breakdown of model compounds.

The metal complexes of PSDTA were not heated in the air oven prior to TG. They started decomposition just above $100{ }^{\circ} \mathrm{C}$. The initial weight loss may be due to the absorbed moisture as the ir spectra did not show the presence of coordinated water. The observed weight loss in the $100-150{ }^{\circ} \mathrm{C}$ range also showed correspondence with the calculated loss of water molecules. The loss of water molecules in this temperature range further suggested its absence in coordination sphere.

A perusal of Fig. 2B indicated that PSDTA coordination polymers show superior thermal stability than the ligand and do not decompose completely even up to $700{ }^{\circ} \mathrm{C}$. Thermal analysis data for PODTA and its complexes with Co (II)-Sal, Cu (II)-Sal and Ni (II)-Sal are given in Fig. 2C. On the basis of initial decomposition temperature the following order of thermal stability can be given:

PODTA-Co (II)-Sal $<$ PODTA $<$ PODTA-Ni (II)Sal' $<$ PODTA-Cu (II)-Sal'

PODTA-Co (II)-Sal' complexes was found to have lower thermal stability than the ligand PODTA. In several other cases, when the metal ions were introduced in the polymer chains, such behavior was observed, which may be due to setting up of some favorable condition for fast degradation. A few metal ions behave like catalyst during degradation process of the polymers at high temperature [43]. The other two complexes PODTA-Ni (II)-Sal' and PODTA-Cu (II)-Sal' show enhanced stability. On the basis of residual weight $(\%)$ at $700{ }^{\circ} \mathrm{C}$, the order of thermal stability was found to be as;

PODTA-Co (II)-Sal' < PODTA-Ni (II)-Sal' $<$ PODTA < PODTA-Cu (II)-Sal'

Irving-Williams found that the order of $\mathrm{Co}$ (II) $<\mathrm{Ni}$ (II) $<\mathrm{Cu}$ (II) holds for the stability of complexes irrespective to the nature of coordinated ligand or of the number of ligand molecules involved. This order holds good for metal complexes of PODTA in the present study.

However, in our study of poly (ethylene aspartate)metal complexes [44] we found that correlation between chemical structure and stability could not be made for polymeric complexes by comparison with data for analogous non-polymeric complexes, as the polymer chain environment often affects the course of degradation. The similar observation was experienced in the study of thermal degradation pattern of aliphatic-aromatic polyamide metal complexes [45].

For PODTA complexes probably the stoichiometry of the complexes may also be responsible for observed anomaly in the order of stability. For PODTA-Cu (II)-Sal' complexes 1:1 stoichiometry has been inferred from the analytical data which suggested a linear polymeric structure. The highest stability of this complex may be due to its highest molecular weight among the other complexes. The TG curves of PMDTA and its complexes show that the order of thermal stability on the basis of initial decomposition temperature was found to be:

\section{PMDTA-Cu (II)-Naphthal' > PMDTA-Co (II)-Sal' - PMDTA-Co (II)-Naphthal' > PMDTA}

Comparison of the energy of activation as calculated using the Fuoss method [46] showed that coordination polymers were thermally more stable than PMDTA. It was observed that the degradation pattern and stability of metalcomplexes of salicyladehyde and 2-hydroxy-1naphthaldehyde were almost similar. It was expected that electron delocalization through an additional aromatic ring may stabilize the complex but probably the steric crowding nullifies the electronic effect.

\section{Conclusion}

Phospsphorylation technique was found to be quite convenient method for preparation of amino terminated polyamides. Introduction of metal ions in polyamide chains through Schiff's base formation resulted in enhanced thermal stability. Further detailed study on porosity and crystal structure may suggest their application in adsorption, catalysis, etc.

\section{Reference}

1. Yaghi, O.; O'Keeffe, M.; Nathan, W.; Ockwig, H.; Eddaoudi, M.; Jaheon, K. Nature. 2003, 423, 705-714. 
DOI: 10.1038 /nature 01650.

Parlak, O.; Turner, A.P.F.; Tiwari, A. Advanced Materials, 2014, 26 , 482.

Tiwari, A.; Deshpande, S.; Kobayashi, H.; Turner, A.P.F. Biosensors and Bioelectronics, 2012, 35, 224.

2. Kurth, D. Science and Technology of Advanced Materials. 2008, 9 (1), 014103.

DOI: $10.1088 / 1468-6996 / 9 / 1 / 014103$.

Modi, C.K.; Trivedi, P.M. Advanced Materials Letters, 2012, 3, 149. DOI: $\underline{10.5185 / \text { amlett.2011.10313 }}$

3. Whittell, G.; Manners, I. Advanced Materials. 2007, 19 (21), 34393468 . DOI: $\underline{10.1002 / \mathrm{adma} .200702876 .}$.

Tiwari, A. Journal of Polymer Research, 2008, 15, 337.

Tiwari, A. Journal of Macromolecular Science, Part A: Pure and Applied Chemistry, 2007, 44, 735.

4. Kurth, D.; Higuchi, M. Soft Matter. 2006, 2 (11), 915-927.

DOI: $10.1039 / \mathrm{b} 607485 \mathrm{e}$.

Mishra, A. P.; Tiwari, A.; Jain, R.K. Advanced Materials

Letters, 2012, 3, 213.

DOI: $10.5185 /$ amlett.2011.9307

5. Brassinne, J.; Fustin, C.A.; Gohy, J.F. Journal of Inorganic and Organometallic Polymers and Materials. 2013, 23 (1), 24-40.

DOI: $10.1007 / \mathrm{s} 10904-012-9757-\mathrm{x}$.

Tiwari, A.; Terada, D.; Yoshikawa, C.; Kobayashi, H. Talanta, 2010, $82,1725$.

Tiwari, A. Journal of Inorganic and Organometallic Polymers and Materials, 2009, 19, 361.

6. Zhang, J.; Su C.Y. Coord. Chem. Rev. 2013, 257, 1373-1408.

DOI: org/10.1016/j.ccr.2013.01.005.

7. Ishiwata, T.; Furukawa, Y.; Sugikawa, K.; Kokado, K.; Sada, K. J Am. Chem. Soc. 2013, 135, 5427-5432.

DOI: $10.1021 / \mathrm{ja} 3125614$.

8. Stuart, L.; James. Chem. Soc. Rev. 2003, 32, 276-288

DOI: $10.1039 / \mathrm{b} 200393 \mathrm{~g}$.

9. Angelica, V.; Cazacu, M.; Zaltariov, M.F.; Shova S.; Constantin, T.; Airinei, A. Polymer. 2013, $54,4353$.

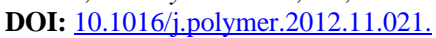

10. Khan, N.; Parveen, S.; Rasool, R. Journal of Coordination Chemistry. 2010, 63 (22),3944-3955.

DOI: $10.1080 / 00958972.2010 .526207$.

11. Modi, C. Spectrochimica Acta. 2009, A 71,1741-1748 DOI: $10.1016 /$ j.saa.2008.06.024.

12. Bajpai, U.D.N.; Misra, D.D.; Bajpai, A. J. Macromol. Sci.-Chem. 1983, $A 19(8), 823-825$.

DOI: $10.1080 / 00222338308060778$.

13. Bajpai, U.D.N.; Misra, D.D.; Bajpai, A. J. Macromol. Sci.-Chem. 1986, $A 23(6), 605-617$.

DOI: $10.1080 / 00222338608058499$.

14. Bajpai,A.; Bajpai U.D.N.; Khandwe, M. Polym. Bull 1990, 23, 51-56. DOI: $10.1007 / \mathrm{BF} 00983963$

15. Bajpai,A.; Bajpai U.D.N.; Khandwe, M.; Macromolecules 1991, 24, 5203-5207.

DOI: $10.1021 / \mathrm{ma} 00018 \mathrm{a} 027$.

16. Bajpai,A.; Bajpai U.D.N.; Rai, S. J. Appl. Polym. Sci.1993, 48, 1241. DOI: $10.1002 / a p p .1993 .070480712$.

17. Bajpai,A.; Bajpai U.D.N.; Rai, S. Polymer International 1993, 32(3), 215-220.

DOI: $10.1002 /$ pi.4990320302.

18. Bajpai,A.; Bajpai U.D.N.; Rai, S. Polymer J 1997, 29(1), 44-48.

19. Bajpai,A.; Bajpai U.D.N.; Rai, S. Polymer.J.1998,69(4),751-759, DOI: $\quad 10.1002 /(\mathrm{SICI}) 1097-4628(19980725) 69: 4<751::$ AIDAPP13>3.0.CO;2-S.

20. Rai, S.; Bajpai, A.; Lokhandwala S.; Journal of Polymers 2013, Article ID 278576 (Article in press). DOI:.10.1155/2013/278576.

21. Bajpai, U.D.N.; Misra, D.D.; Bajpai, A.; Collection Czechoslova Chem. Commun. 1983, 48, 3329.

DOI: $10.1135 / \mathrm{cccc} 19833329$.

22. Bajpai, A.; Khare, K. Journal of Macromolecular Science, Part A 2006, 41(3), 275-293.

DOI: $10.1081 / \mathrm{MA}^{-1} 20028207$.

23. Selvi, C; Nartop D. Spectrochim Acta A Mol Biomol Spectrosc, 2012, 95, 165-71.

DOI: $10.1016 /$ j.saa.2012.04.079.

24. Nishat, N; Raza R; Shadma P; Shamim A. Applied Polymer Science, 2011, 122-4, 2756-2764.
DOI: $10.1002 / a p p .34100$

25. Cleiton, M.; Daniel, L.; Luzia, V.; Rosemeire, B.; Deesende, A.; Cleide V.; Fatima, A. Journal of Advanced Research 2011, 2(11), 18.

DOI: $10.1016 / \mathrm{j}$. bbr.2011.03.031.

26. Sabry,N.; Eman, M.; Mohamed, A.; Omar, A.; El-Galil, A. Journal of Chemistry. 2013 Article ID 106734, 6.

DOI : $10.1155 / 2013 / 106734$.

27. Riyadh, M.; Ahmed, Yousif,E.; Hasan, A.; Mohamad, J.;The Scientific World Journal 2013, Article ID 289805. DOI: $10.1155 / 2013 / 289805$.

28. Aderoju, A.; Osowole, I.; Oladunni, M.; International Journal of Inorganic Chemistry. 2012, 206417.

DOI: $10.1155 / 2012 / 206417$.

29. Nair, R.;Shah, A..; Baluja, S.;Journal of the Serbian Chemical Society. 2006, 71(7), 733-744. DOI: $10.2298 / \mathrm{JSC} 0607733 \mathrm{~N}$.

30. Aoki,H.; Coffin,D.R.; Hancock,T.A.; Harwood,D.;Lenk,R.S.; Fellers,J.F.; White, J.L. J. Polym. Sci. Polym.Symp.1978, 65, 29. DOI: $10.1002 /$ polc. 5070650105.

31. Puffer, R.; Sebenda, J. J.Polym.Sci.C., 1977, 16, 79.

32. Bellamy, L. J. The Infrared Spectra of Complex Molecules, Wiley, New York. 1964.

33. Colthup, N.B.; Daly, L.H.; Wiberly, S.E. Introduction to Infrared and Raman Spectroscopy, Academic Press, New York.1969, 270.

34. Fisher, A.M.; Stoufer, R.C. Inorg.Chem. 1966, 5,1172.

35. Barefield, E.K.; Busch D.H.; Nelson, S.M. Q. Rev. 1963, 85,260.

36. Gray, H.B.; Balhaueen, C.J. J.Am.Chem.Soc.1963, 85, 260.

37. Hatfield, W.E.; Muto,Y. Inorg.Chem. 1965,4,97

38. Sacconi, L.; Ciampolin, M. J. Chem Soc.1965, 276

39. Dine-Har, R.A.; Moore, B.J.; Wright, W.W. J.Polym.Sci.1964, B2, 369.

40. Sazanov, Yu.N.; Shibaev, L.A.; Antonova,T.A. J. Thermal Anl. 1980, 18,65 .

41. Nishizaki,S.; Fukani,A. J.Polm.Sci., 1968, $A^{-1} 6,1769$

42. Blake, E.S.; Hammann, W.C.; Edwards,J.W.; Reichard,T.E., J.Chem.Engg.Data.1961, 6,87.

43. Bajpai, U.D.N.; Bajpai, A.; Rai, S. Synth. \& React. Inorg. MetOrg.Comp. 1994, 24(10), 1719-1732.

44. Irving, H.; Williams, R.J.P., J. Chem Soc., 1953, 3192.

45. Bajpai, U.D.N.; Bajpai,A.; Rai, S.; Polymer International. 1993, 32, 215.

46. Fuoss, R.M.; Salyer, I.O.; Wilson,H.S. J.Polym.Sci.1962, A2,3147. 